\title{
EDITORIAL
}

\section{Coming of age}

\section{Ian C Duncan} FFRad (D) SA

Unitas Interventional Unit Centurion, and Sunninghill Hospital

Sandton Johannesburg
The South African Journal of Radiology is now coming of age. 1 With the appointment of an Editor-in-Chief, the creation of a new academic editorial board and the use of a more formalised peer-review system for all submissions, the journal is set to raise its profile among other radiological publications. With the implementation of the above changes we will eventually attempt to have the journal indexed internationally, thereby transforming it into the more substantial publication that South African radiology deserves. Our standards of training and practice are high and there is good demand for our expertise - let our journal in turn reflect this.

Many thanks go to Professor J P van Niekerk for his encouragement and support in making this transition and for facilitating our growth. 